\title{
USO DO BRINQUEDO TERAPÊUTICO NO CUIDADO DE ENFERMAGEM À CRIANÇA COM LEUCEMIA HOSPITALIZADA*
}

Alexandra de Souza ${ }^{1}$, Luciane Favero²

\begin{abstract}
RESUMO: Pesquisa qualitativa exploratório-descritiva objetivou identificar o conhecimento da equipe de enfermagem acerca da utilização do brinquedo terapêutico, discutir os benefícios e particularidades do seu uso e propor sua implantação. Participaram quatro profissionais de uma unidade hospitalar oncopediátrica. Os dados foram obtidos durante a técnica de discussão de grupo em dois encontros de cerca de meia hora cada, no local de estudo, no mês de julho de 2010. Após análise temática, quatro categorias remeteram ao desconhecimento da utilização do brinquedo terapêutico; à expectativa e à adesão do seu uso; e à presença do brinquedo terapêutico durante os cuidados à criança hospitalizada. Visitas semanais foram realizadas durante quatro meses com o intuito de observar a adesão e constatou-se o uso desta estratégia durante o cuidado de enfermagem. São necessários estudos que contemplem maior número de participantes para que outros membros da equipe sejam capacitados e sensibilizados para a utilização do brinquedo terapêutico.
\end{abstract}

PALAVRAS-CHAVE: Brinquedo; Cuidados de enfermagem; Criança hospitalizada.

\section{USE OF THERAPEUTIC TOYS IN NURSING CARE OF THE HOSPITALIZED CHILD WITH LEUKEMIA}

ABSTRACT: This exploratory-descriptive qualitative research aimed to identify the nursing team's knowledge concerning the use of therapeutic toys, discuss the benefits and specificities of its use, and propose its implantation. Four professionals participated, from a pediatric oncology hospital center; the data was obtained through the technique of group discussion, in two meetings of about thirty minutes, in the location of the study, in July 2010. After thematic analysis, there were four categories: ignorance of the use of the therapeutic toy; expectation of and adherence to its use; and the presence of the therapeutic toy during provision of care to the hospitalized child. Weekly visits were undertaken over four months with the aim of observing adherence and use of this strategy was observed during nursing care. Studies including greater numbers of subjects are needed, so that other members of the team may be trained and made aware of the use of therapeutic toys.

KEYWORDS: Toy; Nursing care; Hospitalized child.

\section{USO DEL JUGUETE TERAPÉUTICO EN EL CUIDADO DE ENFERMERÍA AL NIÑO HOSPITALIZADO CON LEUCEMIA}

RESUMEN: Investigación cualitativa exploratorio-descriptiva cuyo objetivo fue identificar el conocimiento del equipo de enfermería acerca de la utilización del juguete terapéutico, discutir los beneficios y particularidades del uso de este y proponer su implantación. Participaron cuatro profesionales de una unidad hospitalar oncopediátrica. Los datos fueron obtenidos durante la técnica de discusión de grupo en dos encuentros de aproxmadamente media hora cada, en el sitio de estudio, en el mes de julio de 2010. Después del análisis temático, cuatro categorías apuntaron el desconocimiento de la utilización del juguete terapéutico; de la expectativa y de la adhesión de su uso; y de la presencia del juguete terapéutico durante los cuidados al niño hospitalizado. Visitas semanales fueron realizadas por cuatro meses con la finalidad de observar la adhesión y se constató que hubo uso de esta estrategia para el cuidado de enfermería. Son necesarios estudios que contemplen mayor número de participantes para que otros miembros del equipo sean capacitados y sensibilizados para la utilización del juguete terapéutico. PALABRAS CLAVE: Juguete; Cuidados de enfermería; Niño hospitalizado.

*Extraído do Trabalho de Conclusão do Curso de Graduação em Enfermagem apresentado à Universidade Tuiuti do Paraná em 2010.

${ }^{1}$ Enfermeira.

${ }^{2}$ Enfermeira. Mestre em Enfermagem. Doutoranda pelo Programa de Pós-Graduação em Enfermagem da Universidade Federal do Paraná. Professora do Curso de Graduação em Enfermagem da Universidade Positivo. Membro do Núcleo de Estudos Cuidado e Ensino em Saúde.

Autor correspondente:

Recebido: $18 / 01 / 2012$

Luciane Favero Aprovado: 16/10/2012

Universidade Positivo

Rua Urbano Lopes, 214 - 80050-520 - Curitiba-PR-Brasil

E-mail: lucianefavero@yahoo.com.br 


\section{INTRODUÇÃO}

A hospitalização pode ser vista como situação perturbadora na vida de qualquer ser humano e apresenta contornos especiais quando ocorrida na infância, pois é capaz de afetar a vida familiar, implicando em mudança de rotina de todos os seus membros ${ }^{(1)}$.

Durante os primeiros anos de vida, as crianças são vulneráveis às doenças e à hospitalização, que tem implicações por representarem mudança do estado habitual de saúde e da rotina familiar, além de as crianças possuírem número limitado de mecanismos para lidar com eventos geradores de estresse, tais como a perda do controle, resultante da restrição física, mudança da rotina e da dependência imposta, as lesões corporais e a dor, que decorre, principalmente, da realização de procedimentos ${ }^{(2)}$.

Como forma de prevenir ou minimizar a separação familiar algumas estratégias são apresentadas. A primeira refere-se ao preconizado no Artigo 12 do Estatuto da Criança e do Adolescente (ECA) ${ }^{(3)}$ que garante o direito do acompanhamento integral e ininterrupto por familiar ou responsável legal durante a hospitalização de menores. Outra estratégia é o cuidado centrado na família ${ }^{(2)}$, que reconhece seu papel na vida da criança, podendo ser considerada parceira na realização dos cuidados, o que em alguns estudos é descrito como cuidado compartilhado ${ }^{(1,4-5)}$.

O cuidado compartilhado é muito utilizado em unidades de internação hematológicas, pois muitos cuidados de enfermagem são realizados com as crianças hospitalizadas nesses setores, embora esses sejam imprescindíveis para a restauração da condição de saúde, desgastam tanto a criança quanto o familiar acompanhante, devido ao longo processo de hospitalização e rehospitalização que enfrentam; intervenções frequentes, muitas vezes dolorosas, além do sofrimento com a patologia de base, seus significados e estigmas.

As doenças neoplásicas são a principal causa de morte em crianças maiores de um ano e quase a metade dessas neoplasias são hematológicas, com destaque para as leucemias ${ }^{(2)}$. A leucemia consiste em proliferação irrestrita de leucócitos imaturos nos tecidos hematopoiéticos do organismo, não tendo, na sua maioria, origem definida. Tem como principal característica o acúmulo de células jovens na medula óssea e, consequentemente, na corrente sanguínea, sendo considerada a causa mais comum de câncer na infância ${ }^{(2)}$.

A criança acometida pela leucemia pode vir a sofrer alteração em seu cotidiano, capaz de apresentar atraso escolar e relacionamento dificultoso com outras crian- ças, devido à longa permanência em ambiente hospitalar, além de menor tolerância a procedimentos dolorosos.

Para minimizar esses efeitos, decorrentes do processo de hospitalização, além de outras estratégias, tem-se a utilização do brinquedo terapêutico (BT). Quando os membros da equipe multiprofissional, em especial os da enfermagem, utilizam esta estratégia são capazes de perceber que os procedimentos são mais bem aceitos pela criança e pelo cuidador familiar, além de poder acarretar diminuição do estresse e da ansiedade, contribuir para a satisfação dos familiares e realização de um cuidado atraumático ${ }^{(6-8)}$.

O BT é um brinquedo estruturado para a criança aliviar a ansiedade causada por experiências atípicas para a idade, que costumam ser ameaçadoras e requerem mais do que recreação para resolver a angústia associada. Deve ser utilizado sempre que a criança tiver dificuldade em compreender ou lidar com uma experiência difícil, ou ainda, necessitar ser preparada para procedimentos invasivos e/ou dolorosos ${ }^{(6)}$.

Ele pode ser classificado em: dramático - que tem a finalidade de permitir à criança revelar experiências que tem dificuldade de verbalizar, a fim de aliviar tensão, expressar sentimentos, necessidades e medos; capacitador de funções fisiológicas - utilizado para capacitar a criança para o autocuidado, de acordo com o seu desenvolvimento, condições físicas e prepará-la para aceitar a sua nova condição de vida; e o instrucional - indicado para preparar e informar a criança dos procedimentos terapêuticos a que será submetida, a fim de envolvê-la na situação e facilitar sua compreensão a respeito do procedimento a ser realizado ${ }^{(9)}$.

Acredita-se que, por meio da exploração do brinquedo, a criança adquire conhecimentos para manipular os objetos e construir diferentes conceitos, além de estimular o raciocínio lógico para criar estórias, conversar e dramatizar sobre o objeto manipulado ${ }^{(8)}$.

Nesse contexto, as questões que nortearam este estudo foram: como utilizar o BT durante o cuidado de enfermagem realizado à criança com leucemia em processo de hospitalização? Qual o conhecimento da equipe de enfermagem sobre a utilização do BT?

Para responder estas questões objetivou-se nesta pesquisa identificar o conhecimento da equipe de Enfermagem acerca da utilização do BT; discutir com a equipe de enfermagem os benefícios e particularidades do uso do BT à criança hospitalizada; e propor a implantação do uso do BT durante o cuidado de enfermagem realizado à criança portadora de leucemia em processo de hospitalização. 


\section{MÉTODO}

Trata-se de uma pesquisa qualitativa do tipo exploratório-descritiva. Utilizou-se a técnica de Discussão de Grupo como estratégia de coleta de dados, a qual permite "complementar informações sobre conhecimentos peculiares a um grupo em relação a crenças, atitudes, percepções", sendo considerados importantes as opiniões, as relevâncias e os valores dos participantes ${ }^{(10: 69)}$.

A pesquisa foi realizada entre os meses de julho a novembro de 2010 em uma unidade clínica de internação pediátrica de uma instituição hospitalar de grande porte localizada no Município de Curitiba-Paraná que recebe crianças de várias especialidades, entre elas, hematologia.

A população da pesquisa foi composta pela equipe de enfermagem atuante no período matutino na referida unidade, formada por duas enfermeiras, um técnico e cinco auxiliares de enfermagem.

Foram delimitados os seguintes critérios de inclusão: ser membro da equipe de enfermagem atuante na unidade local do estudo no período matutino e presente durante o período de coleta de dados. Desse modo, quatro dos seis membros da equipe, que preencheram os critérios descritos, tornaram-se participantes do estudo, sendo três auxiliares e um técnico em enfermagem.

A pesquisa passou por apreciação do Comitê de Ética e Pesquisa do Hospital sede do estudo, sendo aprovada sob o número 2151046/2010-2. Aos participantes, foram explicados os objetivos, a participação de caráter voluntário e solicitada a assinatura do Termo de Consentimento Livre e Esclarecido, atendendo à Resolução 196/96 do Conselho Nacional de Saúde. Garantiu-se o anonimato dos participantes ao serem utilizados codinomes de personagens de histórias infantis, tais como Cinderela, Branca de Neve, Alice e Rapunzel.

Os dados foram coletados em duas reuniões de grupo, compostas por quatro profissionais. Os encontros ocorreram na própria unidade hospitalar e tiveram duração média de meia hora cada, sendo conduzidos pelos autores, aqui denominados de animadores. As reuniões foram gravadas em áudio e posteriormente transcritas. Para conduzir os encontros, o animador fez uso de um guia de temas que contemplava questões referentes ao conhecimento da equipe sobre BT; reconhecimento de benefícios ou particularidades do seu uso; além de questões referentes à possibilidade de esta prática se tornar permanente na unidade. Para a realização das reuniões houve a colaboração de uma acadêmica de Enfermagem que desempenhou a função de observadora, também utilizou-se o diário de campo, como fonte de dados.
Durante a primeira reunião ocorreu a apresentação dos objetivos do estudo, a promoção de entrosamento e troca de informações entre os participantes e a identificação dos conhecimentos do grupo acerca da temática. Ao final, a animadora procedeu à teorização com o resgate das falas dos participantes, fundamentando a discussão.

No segundo encontro, a animadora promoveu a sensibilização dos participantes com a proposta de confecção de um BT instrucional pelos participantes da pesquisa. Esta também demonstrou uma sessão de cuidados à criança hospitalizada com a utilização do BT instrucional, conforme solicitação dos participantes.

Após as duas reuniões, houve visitação semanal à unidade sede do estudo para a observação da adesão à proposta realizada. Tais visitas foram estendidas até o final do mês de novembro de 2010, período que possibilitou o acompanhamento das práticas de cuidado realizadas pelos participantes da pesquisa.

Os dados coletados na discussão de grupo e registrados no diário de campo foram analisados por meio da análise temática ${ }^{(10)}$.

\section{RESULTADOS}

Emergiram dos dados quatro categorias temáticas que explicitam as discussões realizadas com o grupo de participantes, descritas a seguir.

\section{Desconhecimento acerca dos conteúdos teórico-práticos para a utilização do BT com a criança hospitalizada}

Esta categoria revela as dificuldades relativas ao conhecimento dos participantes acerca da utilização do BT. Pode-se observar que os participantes não explicitaram claramente a forma de utilização do brinquedo durante os cuidados realizados com a criança hospitalizada, mas, apenas afirmaram que já presenciaram outro profissional realizando esse cuidado, sem enfoque no porquê, como e para quê utilizar, como ilustrados nos recortes:

[...] aqui [nesta unidade de internação] só vi a Enfermeira usar, e vi no $13^{\circ}$ andar, mas eu não usei ainda [...]. (Branca de neve)

[...] eu vi no $13^{\circ}$ andar [unidade de cirurgia pediátrica que utiliza o BT nos cuidados de enfermagem] e a enfermeira tem o [boneco] dela também, mas eu não usei [...]. (Cinderela) 
A enfermeira da unidade que realiza atividades assistenciais possui um boneco que simula a utilização do cateter totalmente implantado, tecnologia muito utilizada pela equipe médica em crianças em uso de quimioterapia. Assim, as crianças que utilizam tal dispositivo e as suas famílias conhecem o manuseio e o funcionamento deste dispositivo por intermédio do boneco. Porém, tal prática é realizada, exclusivamente, pela enfermeira e apenas para esse procedimento.

\section{Expectativas frente à possibilidade de uso do BT}

O desconhecimento é um agente gerador de ansiedade, que pode prejudicar a adesão do profissional a novas tecnologias de cuidado como o BT. Ao serem questionados sobre a possibilidade de uso dessa estratégia durante a realização do seu trabalho com as crianças, os participantes verbalizaram expectativas positivas. Porém deixaram claro que tinham dúvidas com relação à sua implementação, como pode ser observado:

Prá mim, acredito que vai ser bem bom, pois com o brinquedo da enfermeira, a gente vê que fica mais claro o procedimento e até mais fácil na hora do curativo, $e$ após a cirurgia, a criança deixa mexer. E até mesmo com os pequenos [crianças menores], a gente não tem tanto problema. (Cinderela)

Vai ser bom principalmente na hora da punção venosa, pois quando vamos pro quarto não sabemos o quanto vamos demorar. E a criança vaificar mais calma, pois sabe o que vai ser feito. E se tivermos uma boa explicação na hora de utilizar o brinquedo, vai ser bom e com certeza vamos usar sempre. (Alice)

Vai ser bem produtivo se aprendermos a usar. Pois aqui não temos outra experiência, só o da enfermeira mesmo. Tinha uma criança aqui que uma colega usou o brinquedo mesmo sem saber o que significava, pois nós tínhamos uma criança que não queria tomar medicação via oral. Aí, ela mostrou que a boneca tomava e não tinha problema, ai ela também passou a tomar, então acredito que vai ser bem bom. (Branca de Neve)

Durante a realização das reuniões, os participantes verbalizaram a aceitação da utilização do brinquedo, entendendo que este poderia trazer benefícios. Foram citados maior segurança da criança durante a realização de procedimentos, rápida recuperação após um procedimento doloroso, melhor aceitação da criança e do seu familiar aos cuidados, entre outros. Porém, como nunca haviam utilizado esse instrumento durante o cuidado, havia insegurança quanto ao método da aplicação. Os recortes das falas retratam a expectativa positiva frente à possibilidade de utilização do BT como auxílio no cuidado:

[...] com o brinquedo a gente vai explicar pra criança o que vai acontecer, isso vai acalmar a criança e dar mais segurança. (Alice)

Eu acho que vai ser bem bom prá acalmar a criança [...], e para o acompanhante, vai ser melhor, porque ele vai entender o procedimento. (Branca de neve)

Durante o segundo encontro, conforme descrito, acordou-se que a animadora utilizaria o BT instrucional em uma sessão de cuidados à criança hospitalizada para demonstrar as possibilidades de aplicação, forma de abordagem, envolvimento do imaginário, do lúdico. Isso para que a equipe pudesse vivenciar o processo e ser capaz de se instrumentalizar para sua aplicação posterior, durante os cuidados.

\section{Adesão dos participantes a utilização do BT}

A confecção do BT instrucional foi realizada pelos participantes durante o segundo encontro, e contemplou a montagem de um boneco com características físicas similares às crianças hospitalizadas naquele local (presença de punção venosa, cateter nasal e sem cabelos, por exemplo). Os materiais para a confecção foram disponibilizados e organizados previamente pelos pesquisadores. Esta estratégia foi usada para aproximar os participantes da proposta de implantação do BT no cuidado de Enfermagem. Com a aplicação do BT instrucional pela animadora os participantes puderem observar a técnica de utilização, participar do momento de cuidado realizado com o BT instrucional e esclarecer eventuais dúvidas que persistiam sobre a temática.

A partir desse momento, por meio de visitas semanais à unidade, percebeu-se que os participantes, de maneira gradual, passaram a utilizar o BT instrucional durante a realização dos cuidados de enfermagem. No período de coleta de dados foi possível presenciar a utilização do brinquedo como instrumento terapêutico, como modo de distração para a criança, envolvimento e aproximação com ela e sua família, além da perceptível satisfação de cada profissional envolvido no cuidado.

[...] prá mim foi bem gostoso, eu já tinha a experiência

Cogitare Enferm. 2012 Out/Dez; 17(4):669-75 
da faculdade [...] achei que pode ser usado sempre [...]. (Rapunzel)

[...] prá mim foi bem legal, eles pedindo o brinquedo. Os procedimentos ficaram bem mais fáceis, até mesmo a verificação dos sinais vitais [...]. (Cinderela)

\section{O BT fazendo parte dos cuidados de Enfermagem}

Toda mudança é capaz de gerar ansiedade e, por vezes, resistência, pois sair da zona de conforto, abrir a mente para novas possibilidades, pode não ser fácil para muitas pessoas. A utilização do BT instrucional iniciou-se de maneira tímida, mas, durante as visitas semanais, os participantes verbalizaram, em conversas informais, que a sua utilização era satisfatória não somente para a criança e familiar, mas também para cada profissional.

Para que mudanças ocorram, é necessário respeitar o tempo de cada pessoa, além de proporcionar condições e ferramentas capazes de instrumentalizá-la para o novo. Vivenciar um cuidado diferenciado, ao visualizar a melhor receptividade da criança e seu familiar à abordagem do profissional, ao perceber rápida recuperação após procedimentos dolorosos, foram experiências vivenciadas pelos participantes do estudo, como exemplificado:

[...] teve que ser algo espontâneo nosso e que teve que ser como uma brincadeira. Aí conseguimos fazer dar certo [...]. (Rapunzel)

[a utilização do brinquedo] é bem produtivo, pois esclarece bem para a criança e para o acompanhante o procedimento que será realizado. É bem bom, pois ajuda bastante, [...] a criança sabe o que está acontecendo com ela. (Branca de Neve)

\section{DISCUSSÃO}

Brincar é importante para a criança, faz parte de seu desenvolvimento, e a equipe de saúde deve reconhecer essa necessidade, propiciar meios para sua realização e incorporar essa prática ao cuidado diário ${ }^{(7)}$. A Resolução do Conselho Federal de Enfermagem (COFEN) n. 295, no artigo $1^{\circ}$, afirma que é competência do enfermeiro atuante na pediatria a utilização da técnica do brinquedo terapêutico durante a realização do cuidado à criança e à família ${ }^{(11)}$. Portanto, mais que uma alternativa de cuidado é um dever da enfermeira, que se estende à equipe por ela coordenada, a qual desenvolve atividades profissionais em alas de internação pediátricas.

Na unidade estudada há iniciativa, ainda que pequena, de uma das enfermeiras que, por meio de um boneco, dramatiza a situação de inserção do cateter totalmente implantado, procedimento relativamente comum em unidades de atendimento oncológico. Porém, tal iniciativa, apesar de importante, é restrita e não contempla os demais cuidados a serem realizados com a criança e nem os demais membros da equipe. Essa equipe precisa ser capacitada para oferecer à criança o BT, com o intuito de realizar uma aproximação e formação de vínculo terapêutico, orientá-la acerca dos procedimentos e cuidados a serem realizados. Esses, visando à diminuição do estresse, à rápida recuperação após a realização de procedimentos dolorosos e à possibilidade de minimizar o risco de desenvolvimento de traumas decorrentes do processo de hospitalização.

Assim, espera-se que a atividade realizada com o grupo de participantes desta pesquisa seja a primeira de muitas outras iniciativas a serem implementadas para a disseminação do conhecimento acerca das práticas de cuidar mediante a estratégia do BT. Nesse sentido, um estudo brasileiro na temática do brinquedo constatou que os profissionais de enfermagem reconhecem de maneira gradual a utilização do brinquedo no cuidado prestado, sendo este cuidado utilizado, inicialmente, para cumprir a função recreacional. Isso se fundamenta na função catártica do brinquedo, que tem sido usado, não só como meio de alívio para as questões impostas pela doença, hospitalização e procedimentos, mas também como possibilidade de comunicação, na qual as enfermeiras podem dar explicações e receber informações de cada criança sob seus cuidados ${ }^{(12)}$.

Porém, faz-se necessária a instrumentalização dos profissionais de saúde para que possam conhecer e utilizar o BT durante a realização de cuidados junto à clientela pediátrica. Desse modo, o conhecimento adquirido e a motivação percebidos mostram que é possível a mudança de práticas incorporadas na rotina de cuidados por outras, capazes de beneficiar todos os envolvidos no processo, desde que haja instrumentalização teórica e prática, além de sensibilização para a mudança.

Em estudo realizado no estado de São Paulo sobre o ensino do BT nos cursos de graduação em Enfermagem foi possível constatar que das 49 instituições pesquisadas, 38 apresentam a temática na disciplina de Enfermagem pediátrica. Mas, a carga horária variou entre uma e vinte horas, distribuídas entre teoria e 
prática $^{(9)}$. Tal fato faz com que seja questionado o real aprendizado ou a possibilidade de sensibilização do aluno e futuro profissional que recebe apenas uma hora entre conteúdo teórico e prático sobre o uso do BT.

De posse do conhecimento necessário e visualizando o potencial terapêutico do brinquedo nos cuidados, é comum o reconhecimento de seus benefícios às crianças, família e equipe. Mas, algumas barreiras ainda se fazem presentes, como a falta de tempo e de profissionais, as demandas do serviço e a ausência de infraestrutura sendo as principais justificativas para o não uso do BT pela equipe de Enfermagem ${ }^{(7,9)}$. Tal situação também foi vivenciada na unidade desse estudo, visto o reduzido número de profissionais atuantes e recusas para participar relacionadas a falta de tempo e excesso de atividades.

Para que a utilização do BT possa fazer parte da rotina diária de cuidados da equipe multiprofissional, em especial a de Enfermagem, são necessários, além da capacitação e instrumentalização para seu uso, o incentivo diário e a demonstração por aqueles com maior habilidade. Também o cumprimento da legislação específica, como a Resolução do $\operatorname{COFEN}^{(1)}$ e da Lei n.11.104/05, que preconiza a obrigatoriedade de instalação de brinquedoteca nas unidades que ofereçam atendimento pediátrico em regime de internação ${ }^{(13)}$.

\section{CONSIDERAÇÕES FINAIS}

Consideramos que um dos papéis da pesquisa em Enfermagemé disseminar conhecimento e, com isso, contribuir para a melhoria dos cuidados prestados aos clientes sob nossa responsabilidade. Dessa forma, a realização deste estudo proporcionou identificar o conhecimento dos membros da equipe de enfermagem atuantes em uma unidade hospitalar oncopediátrica acerca do uso do BT instrucional, durante os cuidados prestados as crianças em processo de hospitalização. A partir do conhecimento relatado e discutido pelo grupo de participantes, tivemos a possibilidade de teorizar a respeito, construir instrumentos capazes de aplicar o conhecimento na prática de cuidar, além de demonstrar sua utilização como forma de visualização e ampliação de saberes.

Algumas dificuldades foram sentidas, como o número reduzido de participantes, devido à diminuição do número de colaboradores presentes na unidade em estudo e ao receio de exposição, por parte de alguns, em participar da pesquisa, o que levou a não aceitação do convite para participar do estudo por dois profissionais. Com o andamento da pesquisa, foi possível perceber, por meio da comunicação verbal, e não verbal, também registrada no diário de campo, o interesse, curiosidade e empolgação frente à nova possibilidade de cuidado. Os participantes passaram a utilizar o BT durante sua jornada de trabalho e, com o passar dos dias, passaram a ser solicitados pelas próprias crianças, fato que facilitou a incorporação da nova prática.

Ao final do estudo, percebeu-se que a cada novo cuidado, desde os mais simples aos mais complexos, o BT se fazia presente. E, os participantes, anteriormente inseguros devido à falta de conhecimento teórico/ prático, passaram a utilizar o BT durante os cuidados, e a acreditar na viabilidade e nos benefícios do cuidado associado ao BT. Esses entenderam esta prática não como mais uma atividade a ser realizada, mas como algo que facilitará sua realização, além de proporcionar maior alegria, segurança e aceitação pela criança.

Portanto, a maior contribuição trazida por esse estudo refere-se à instrumentalização e sensibilização dos participantes do estudo de uma unidade de hematologia infantil, local da pesquisa, para um cuidado à criança e sua família, mediante a incorporação da técnica do BT instrucional no dia a dia de cuidados de enfermagem prestados a essa clientela. Porém, é necessário investimento em novos estudos que possam contemplar maior número de participantes, de forma que todos os membros da equipe de enfermagem possam ser capacitados e sensibilizados para a utilização da técnica BT à criança hospitalizada.

\section{REFERÊNCIAS}

1. Quirino DD, Collet N, Neves AFGB. Hospitalização infantil: concepções da enfermagem acerca da mãe acompanhante. Rev. Gaúcha Enferm. [Internet] 2010;31(2) [acesso em 07 jan 2012]. Disponível: http:// www.scielo.br/pdf/rgenf/v31n2/14.pdf

2. Hockenberry MJ, editor. Wong, Fundamentos de enfermagem pediátrica. Trad. de Danielle Corbett. $7^{\text {a }}$ ed. Rio de Janeiro: Elsevier; 2006.

3. Ministério da Justiça (BR). Lei n. 8.069, de 13 de julho de 1990. Dispõe sobre o Estatuto da Criança e do Adolescente e dá outras providências, [Internet] 1990 [acesso em 19 jun 2011]. Disponível: http://www. planalto.gov.br/ccivil_03/Leis/L8069.htm\#art17

4. Ferreira JS, Favero L. Os benefícios do cuidado compartilhado entre equipe de enfermagem e familiares cuidadores de criança hospitalizada. Boletim Online de Enfermagem. [Internet] 2009;1(3) [acesso em 07

Cogitare Enferm. 2012 Out/Dez; 17(4):669-75 
jan 2012]. Disponível: http://www.utp.br/enfermagem/ boletim_4_ano3_vol1/pdf\%27s/art1_osbeneficios.pdf

5. Gomes GC, Erdmann AL, Busanello J. Refletindo sobre a inserção da família no cuidado à criança hospitalizada. Rev. enferm. UERJ. [Internet] 2010;18(1) [acesso em 07 jan 2012]. Disponível: http://www.facenf.uerj.br/v18n1/ v18n1a25.pdf

6. Ribeiro PJ, Sabatés AL, Ribeiro CA. Utilização do brinquedo terapêutico, como um instrumento de intervenção de enfermagem, no preparo de crianças submetidas a coleta de sangue. Rev Esc Enferm USP. [Internet] 2001;35(4) [acesso em 07 jan 2012]. Disponível: http://www.scielo.br/pdf/reeusp/v35n4/ v35n4a15.pdf

7. Jansen MF, Santos RM, Favero L. Benefícios da utilização do brinquedo durante o cuidado de enfermagem prestado à criança hospitalizada. Rev Gaúcha Enferm. [Internet] 2010;31(2) [acesso em 07 jan 2012]. Disponível: http://www.scielo.br/pdf/rgenf/ v31n2/07.pdf

8. Favero L, Dyniewicz AM, Spiller APM, Fernandes LA. A promoção do brincar no contexto da hospitalização infantil como ação de enfermagem: Relato de Experiência. Cogitare enferm. [Internet] 2007;12(4) [acesso em 07 jan 2012]. Disponível: http://ojs.c3sl.ufpr. br/ojs2/index.php/cogitare/article/view/10080

9. Cintra SMP, Silva CV, Ribeiro CA. O ensino do brinquedo/brinquedo terapêutico nas Escolas de Graduação em Enfermagem no Estado de São Paulo. Rev Bras Enferm. [Internet] 2006;59(4) [acesso em 07 jan 2012]. Disponível: http://www.scielo.br/pdf/reben/ v59n4/a05v59n4.pdf

10. Minayo MCS. O desafio do conhecimento: pesquisa qualitativa em saúde. 10ª ed. São Paulo: Hucitec; 2007.

11. Conselho Federal de Enfermagem. Resolução n. 295, de 24 de outubro de 2004. Dispõe sobre a utilização da técnica do Brinquedo/Brinquedo Terapêutico pelo Enfermeiro na assistência à criança hospitalizada, [Internet] 2004 [acesso em 07 jan 2012]. Disponível: http://site.portalcofen.gov.br/node/4331.

12. Ribeiro CA, Lima EBS, Sabates AL, Borba RIH, Almeida FA, Rezende MA. O brinquedo e a assistência de enfermagem à criança. Enfermagem atual. 2002;2(24):6-17.

13. Ministério da Educação (BR). Lei n. 11.104, de 21 de março de 2005. Dispõe sobre a obrigatoriedade de instalação de brinquedotecas nas unidades de saúde que ofereçam atendimento pediátrico em regime de internação. Diário Oficial da União, [Internet] 22 mar. 2005. Seção 1:1. [acesso em 07 jan 2012]. Disponível: http://www.planalto.gov.br/ccivil_03/_Ato20042006/2005/Lei/L11104.htm 